\title{
CONCENTRAÇÃO SALINA E FASES DE EXPOSIÇÃO À SALINIDADE DO MELOEIRO CULTIVADO EM SUBSTRATO DE FIBRA DE COCO ${ }^{1}$
}

\author{
NILDO DA SILVA DIAS ${ }^{2}$, ANDRÉ MOREIRA DE OLIVEIRA², \\ OSVALDO NOGUEIRA DE SOUSA NETO ${ }^{3}$, FLÁVIO FAVARO BLANCO ${ }^{4}$, \\ JONATAS RAFAEL LACERDA REBOUÇAS ${ }^{3}$
}

RESUMO - No semiárido, a escassez de água de boa qualidade faz com que os produtores utilizem água salobra para preparar a solução nutritiva. Com o objetivo de investigar a utilização de água salobra na irrigação de meloeiro (Cucumis melo L., cv. AF 015) cultivado em substrato de fibra de coco em casa de vegetação, plantas foram nutridas com soluções salinas de condutividades elétricas $\left(\mathrm{CE}_{\mathrm{s}}\right)$ 1,1 (testemunha); 2,5; 4,0 e 5,5 $\mathrm{dS} \mathrm{m}^{-1}$ aplicadas durante as fases: crescimento vegetativo (10-30 dias após o transplantio-DAT); florescimento (31-50 DAT) e frutificação e maturação (51-70 DAT). O delineamento experimental foi o inteiramente casualizado, com 12 tratamentos arranjados em um esquema fatorial 4x3 (níveis de salinidade $\mathrm{x}$ tempo de exposição dos sais), com três repetições. Houve correlação na perda relativa por incremento de $\mathrm{CE}_{\mathrm{s}}$ das variáveis de crescimento e de produção do meloeiro em função da salinidade da solução nutritiva para cada fase de exposição. As soluções nutritivas preparadas com água salobra podem ser utilizadas no cultivo do meloeiro em substrato de fibra de coco com o mínimo de perdas relativas de massa média de frutos por incremento de $\mathrm{CE}_{\mathrm{s}}$, quando aplicadas na fase de florescimento.

Termos para Indexação - Cucumis melo L. Solução Nutritiva. Cultivo Hidropônico.

\section{SALT CONCENTRATION AND PHASES OF EXPOSURE TO SALINITY OF MELON GROWN IN COCONUT FIBER SUBSTRATE}

\begin{abstract}
Scarcity of good water quality in semiarid region causes producers to use brackish water to prepare the nutrient solution. In order to investigate the use of brackish water in irrigation of greenhousemelon (Cucumis melo L., cv. AF 015) grown in coconut fiber substrate, plants were irrigated with saltine nutrient solutions of electrical conductivities (ECs) of 1.1 (control), 2.5, 4.0 and $5.5 \mathrm{dS} \mathrm{m}^{-1}$, applied during the phases of vegetative growth (10-30 days after transplanting, DAT), flowering (31-50 DAT) and fruiting and ripening (51-70 DAT). The design was completely randomized, with 12 treatments arranged in a $4 \times 3$ factorial design (salinity levels $\mathrm{x}$ exposure time of the salts), with three replications. There was a correlation in the reduction relative to each increased de $\mathrm{EC}_{\mathrm{s}}$ of the growth and yield variables of melon in function of ECs for each phase of exposure. The nutrient solutions prepared with brackish water can be used to grow melons in coconut fiber substrate with minimal reduction relative of mean fruit weight with increasing ECs applied during flowering.
\end{abstract}

Index terms - Cucumis melo L. Nutrient Solution. Hydroponics.

\footnotetext{
'(Trabalho 158-10). Recebido em: 19-07-2010. Aceito para publicação em: 21-01-2011. Pesquisa financiada pelo CNPq ${ }^{2}$ Professor Departamento de Ciências Ambientais e Tecnológica, UFERSA, Caixa Posta 137, 59625 900, Mossoró-RN, Brasil, nildo@ufersa.edu.br; andremoreira@ufersa.edu.br

${ }^{3}$ Estudante de Pós-graduação. UFERSA, Mossoró-RN, Brasil. Emails: neto2006osvaldo@yahoo.com.br, rafaelufersa@hotmail.com ${ }^{4}$ Pesquisador da Embrapa Meio-Norte, Teresina-PI, Brasil. Email: flavio@cpamn.embrapa.com.br
} 


\section{INTRODUÇÃO}

Na região produtora de frutas do Rio Grande do Norte, parte da água utilizada para irrigação é proveniente de poços artesianos profundos, que, apesar da boa qualidade, apresentam alto custo de obtenção, que, às vezes, inviabiliza seu uso na agricultura (MEDEIROS et al., 2003). Entretanto, há também poços abertos no calcário Jandaíra, que, mesmo apresentando custo de obtenção mais baixo, possuem água com níveis elevados de salinidade. Nos cultivos irrigados dessa região, tem sido comum a substituição de água de boa qualidade, isto é, de baixa condutividade elétrica, por água salobra, de elevada condutividade elétrica, dos poços rasos, devido ao baixo custo.

Uma alternativa para esta situação seria misturar águas de qualidade boa com de qualidade inferior e, assim, aumentar a disposição para as culturas. Essa mistura pode permitir a irrigação de áreas maiores, mas não diminui o total dos sais; por esta razão, tornam-se imprescindíveis investigações sobre o uso racional dessas águas salobras, pois a sua utilização indiscriminada pode salinizar os solos, agravando os problemas de desertificação (DIAS et al., 2007).

As plantas têm seu comportamento afetado pela salinidade da água de irrigação de forma diferente em função do seu estágio de desenvolvimento. Segundo Läuchli e Epstein (1990), a interferência da salinidade no comportamento das plantas ocorre de diversas maneiras, podendo causar efeitos osmóticos, tóxicos, indiretos de ordem nutricional e, ainda, problemas de permeabilidade do solo.

Segundo Maas (1990), a tolerância aos sais por uma determinada cultura é ainda afetada por fatores como o estágio de seu desenvolvimento no momento da exposição à salinidade, duração da exposição, condições ambientais, propriedades do solo e do tipo e intensidade do manejo do sistema solo-água-planta. Algumas culturas são tolerantes aos sais durante todo o ciclo vegetativo, outras durante o processo de germinação e/ ou nas fases seguintes de crescimento; no entanto, a maioria das plantas cultivadas é moderadamente sensível ou moderadamente tolerante à salinidade (AYERS; WESTCOT, 1999).

Os cultivos hidropônicos podem constituir uma vantagem quando se utiliza água salobra, pois, neste sistema, inexiste o potencial mátrico, devido ao estado de saturação a que as plantas estão submetidas, fato que possibilita o aumento da tolerância das culturas à salinidade (SOARES, 2007). Deste modo, não haveria contaminação do solo e, como benefício extra, o aproveitamento de fontes alterna- tivas de recursos hídricos e a garantia da produção da agricultura praticada no semiárido. Além disso, o uso da hidroponia é uma importante alternativa em relação ao cultivo tradicional, por permitir o uso mais econômico e eficiente de água e fertilizantes (FURLANI et al., 1999). Entretanto, um dos entraves dessa técnica é o alto custo de produção, principalmente em energia elétrica e solução nutritiva, sendo necessárias investigações que permitam obter cultivos com alta produção e baixo custo, destacando a busca do manejo adequado das águas de condutividade elétrica elevadas.

Levando-se em consideração estes aspectos, objetivou-se, neste trabalho, avaliar os efeitos da salinidade da solução nutritiva em diferentes fases de desenvolvimento da cultura do meloeiro cultivado em substrato de fibra de coco sob condições de ambiente protegido.

\section{MATERIAL E MÉTODOS}

O experimento foi conduzido em casa de vegetação, no Departamento de Ciências Ambientais da Universidade Federal Rural do Semiárido, no Município de Mossoró-RN (latitude de $5^{\circ} 11^{\prime} \mathrm{S}$, longitude de $37^{\circ} 20^{\prime} \mathrm{W}$ e altitude de $18 \mathrm{~m}$ ).

As mudas de meloeiro (Cucumis melo L., cv. AF 015) foram produzidas em bandejas de poliestireno expandido, em 128 células preenchidas com substrato de fibra de coco. Aos 13 dias após o plantio, as mudas foram transplantadas para 36 sacos plásticos de $12 \mathrm{~L}$ contendo uma camada de $2 \mathrm{~cm}$ de brita no fundo, recoberta com telado de náilon e preenchidos com 3,5 kg de fibra de coco (Golden Mix ${ }^{\circledR}$ ), constituindo as unidades experimentais. Estas unidades foram posicionadas em 6 fileiras espaçadas entre si de $1,00 \mathrm{~m}$ e de $0,50 \mathrm{~m}$ entre plantas na fileira, sendo instalados mourões nas extremidades de cada fileira de planta para amarração de 3 fios de arame com intuito de tutorar as plantas.

A solução nutritiva foi preparada com águas de diferentes níveis de salinidade, sendo proveniente de água, de abastecimento $\left(\mathrm{CE}=0,52 \mathrm{dS} \mathrm{m}^{-1}\right)$, água de poço aberto no calcário Jandaíra $\left(\mathrm{CE}=3,7 \mathrm{dS} \mathrm{m}^{-1}\right)$, mistura das águas e a adição de $\mathrm{NaCl}$ à água de poço. Após a obtenção das águas, foram adicionados os fertilizantes da solução nutritiva básica, conforme recomendação de Santos (2002), em que, para cada $100 \mathrm{~L}$ de água, foram adicionados: $805 \mathrm{~g}$ de nitrato de cálcio, $334 \mathrm{~g}$ de nitrato de potássio, $175 \mathrm{~g}$ de fosfato monoamônico, $252 \mathrm{~g}$ de sulfato de magnésio e 10 $\mathrm{g}$ de Quelatec ${ }^{\circledR}$ (mistura sólida de EDTA-chelated contendo os micronutrientes: $0,28 \% \mathrm{Cu}, 7,5 \% \mathrm{Fe}$, 
$3,5 \% \mathrm{Mn}, 0,7 \% \mathrm{Zn}, 0,65 \%$ B e $0,3 \% \mathrm{Mo}$ ).

As plantas de melão foram nutridas com soluções salinas de condutividades elétricas 1,1 (testemunha); 2,5; 4,0 e 5,5 $\mathrm{dS} \mathrm{m}^{-1}$ aplicadas durante as fases: crescimento vegetativo (10-30 dias após o transplantio-DAT); florescimento (31-50 DAT) e frutificação e maturação (51-70 DAT). A solução nutritiva foi fornecida diariamente na água de irrigação, sendo o volume de solução suficiente para preencher o substrato na capacidade máxima de retenção, obtidos com tensiômetros instalados a $20 \mathrm{~cm}$ de profundidade e da curva característica de retenção de água da fibra de coco nos vasos, construída previamente. $\mathrm{O}$ experimento foi conduzido em delineamento inteiramente casualizado, com 12 tratamentos arranjados em esquema fatorial $4 \times 3$ (níveis de salinidade $\mathrm{x}$ fases fenológicas), com três repetições.

A polinização foi efetuada quase que exclusivamente da forma manual, com auxílio de um dedal, em que se retiravam diariamente algumas flores masculinas de diferentes plantas nas primeiras horas do dia. Depois se faziam a emasculação das flores femininas que se apresentavam aptas para a polinização, ou seja, mais desenvolvidas. Esta atividade de polinização ocorreu durante todo o período de florescimento (30-50 DAT).

A colheita dos frutos foi realizada aos 72 DAT, quando atingiram o ponto de maturação fisiológica, ou seja, mudança de coloração da casca de verde para acinzentada e ocorrência de rendilhamento em volta do pedúnculo. A produtividade foi relacionada com a massa média de fruto (MMF), e a espessura da polpa (EP), através de balança eletrônica e paquímetro digital, respectivamente.

As matérias fresca (MFPA) e seca (MSPA) da parte aérea da planta foram obtidas ao término do experimento, retirando-se toda a parte vegetativa de cada planta, excluindo o sistema radicular, determinando-se a massa fresca e, posteriormente, a massa seca após secagem em estufa a $65{ }^{\circ} \mathrm{C}$ até peso constante.

Os dados foram submetidos à análise de variância e regressão linear, utilizando o programa estatístico Genes (CRUZ; REGAZZI, 2001). O rendimento percentual do melão, em função da salinidade para as fases fonológicas da cultura, foi calculado em relação ao rendimento obtido com o tratamento-testemunha. Os valores dos parâmetros de tolerância das culturas à salinidade limiar (SL) e de perda de rendimento relativo por incremento unitário da condutividade elétrica da salinidade limiar (b), do modelo de Maas e Hoffman (1977), foram estimados com o programa SAS versão 9.0 (SAS Institute, 2000).

\section{RESULTADOS E DISCUSSÃO}

Houve efeito significativo da salinidade, da fase de exposição e da interação salinidade $\mathrm{x}$ fase de exposição para todos os parâmetros estudados. Verifica-se efeito linear decrescente dos níveis de salinidade em cada fase de exposição sobre os parâmetros de crescimento do meloeiro, sendo observados decréscimos relativos na massa da parte aérea das plantas por incremento unitário da condutividade elétrica da solução $\left(\mathrm{CE}_{\mathrm{s}}\right)(\mathrm{b})$, nas fases de exposição à salinidade de 10-30, 31-50 e 51-70 DAT de 4,3; 4,1 e 3,2\% por $\mathrm{dS} \mathrm{m}^{-1}$ para a MFPA e de 6,$9 ; 8,1$ e $5,5 \%$ por dS $\mathrm{m}^{-1}$ para a MSPA, respectivamente (Tabela 1). Este fato é um indicativo de que a exposição da planta à salinidade da solução nutritiva, durante a fase de frutificação, tem menor efeito sobre o crescimento vegetativo das plantas.

$\mathrm{O}$ menor efeito dos níveis de $\mathrm{CE}_{\mathrm{s}}$ sobre o crescimento vegetativo das plantas, na fase de frutificação (51-70 DAT), deveu-se ao fato de as plantas já estarem em pleno desenvolvimento vegetativo e, consequentemente, houve menor interferência do efeito osmótico da solução sobre o crescimento das plantas durante esta fase, já que não houve exposição das plantas à salinidade nas fases anteriores.

Com relação ao rendimento de frutos, a exposição à salinidade nesta fase proporcionou menores ganhos de massa média de frutos e de espessura de polpa por incremento da salinidade da solução nutritiva, de - 95,61 $\mathrm{g}$ por $\mathrm{dS} \mathrm{m}^{-1}$ de MMF e - 1,63 mm por $\mathrm{dS} \mathrm{m}^{-1}$ de EP dos frutos (Tabela 2). Nos tratamentos em que a salinidade foi aplicada durante a frutificação, embora as plantas já tivessem maior crescimento vegetativo, o ganho de MMF foi menor com o incremento da $\mathrm{CE}_{\mathrm{s}}$ devido o efeito osmótico da salinidade ter dificultado a absorção de água e nutrientes pela planta, justamente na fase de maior demanda hídrica da planta para suprimento do dreno (fruto) (AYERS; WESTCOT, 1999).

As plantas que sofreram estresse salino apenas no estádio de frutificação (51-70 DAT), registraram menores ganhos de biomassa por incremento de $\mathrm{CE}_{\mathrm{s}}$, o que tornou a planta mais tolerante à salinidade e, possivelmente, através de rotas metabólicas, concentrou os assimilados nos frutos, gerando maior potencial osmótico na planta em relação à solução salina no substrato (AMOR et al., 1999; TAIZ; ZEIGER, 2006).

Quando as soluções nutritivas salinas foram aplicadas na fase de florescimento, as plantas do meloeiro sofreram com os efeitos osmóticos somente entre 31-50 DAT, passando a ser nutridas com 
solução de menor salinidade $\left(1,1 \mathrm{dS} \mathrm{m}^{-1}\right)$ até o final do ciclo, o que compensou os efeitos da exposição da salinidade sobre as plantas, resultando em menor redução no ganho de massa média de frutos por incremento de $\mathrm{CE}_{\mathrm{s}}\left(-56,6 \mathrm{~g}\right.$ por $\mathrm{dS} \mathrm{m}^{-1}$ de MMF) em relação às plantas que se submeteram ao estresse salino nas fases de desenvolvimento vegetativo e frutificação (-70,10 e -95,6 g por dS m de MMF), respectivamente, nesta ordem.

Maas e Hoffman (1977) afirmam que, de maneira geral, a salinidade afeta negativamente as plantas em todos os estádios, sendo que, em algumas culturas mais sensíveis, isto pode variar dos primeiros estádios para os últimos. De acordo com Fageria et al. (2010), a seleção das culturas para tolerância à salinidade deve ser feita no estádio mais sensível; é possível, também, irrigar com água salina durante o estádio de maior tolerância e usar água com baixa salinidade durante o estádio mais sensível. Esses autores relatam que a irrigação com água salobra de $8 \mathrm{dS} \mathrm{m}^{-1}$, no início da floração até a colheita, não afeta significativamente a produção de melão cultivado em solo, em comparação com a água de irrigação com salinidade de $0,2 \mathrm{dS} \mathrm{m}^{-1}$.

Observou-se uma correlação na redução do rendimento relativo do melão em cada fase de exposição para cada nível de salinidade (Figura 1). Em termos de tolerância da cultura à salinidade, pode-se verificar que a taxa de perda de rendimento relativo do meloeiro por incremento unitário da $\mathrm{CE}_{\mathrm{s}}$, para cada fase de exposição, foi de 7,10; 5,70 e $9,7 \%$ por $\mathrm{dS} \mathrm{m}^{-1}$, para $10-30,31-50$ e 51-70 DAT, respectivamente. Medeiros et al. (2003) citam, para a cultura do melão (cv. Orange flash) irrigado com água salobra, perdas de rendimento relativo de $11,37 \%$ por $\mathrm{dS} \mathrm{m}^{-1}$ para cultivo tradicional nas condições de Mossoró-RN.

As reduções relativas nos valores dos parâmetros de crescimento e produção por incremento de $C E_{s}$, em cada fase de exposição, refletem o efeito negativo do potencial osmótico da solução nutritiva sobre as plantas de melão cultivadas em sistema hidropônico devido à inibição da absorção de água pela planta, conforme citado por Ayers e Westcot (1999). Porém, os baixos valores das taxas de perda relativa $(7,1 ; 5,7$ e $9,7 \%$ para as fases de crescimento, floração e frutificação, respectivamente) da curva típica de tolerância (Figura 1) indicam que a produção relativa do meloeiro decresce suavemente com o incremento da salinidade da solução nutritiva, constatando a maior tolerância do meloeiro quando cultivado em substrato de fibra de coco do que em outros meios de crescimento. Por exemplo, em plantas de melão cultivadas em solos sob estresse osmótico durante todo o ciclo da cultura, Alencar et al. (2003) encontraram redução relativa na matéria fresca da parte aérea, de $16,19 \%$ por dS m ${ }^{-1}$, e Dias et al. (2006) constataram perdas relativas no rendimento dos frutos de $14,24 \%$ por $\mathrm{dS} \mathrm{m}{ }^{-1}$ acima da salinidade limiar. Já Amor et al. (1999) registraram perdas de rendimento relativo de $9,6 \%$ em melão (cv. Gália) cultivado em perlita sob condições protegidas quando os níveis de salinidade da solução nutritiva foram aplicados após 14 DAT.

TABELA 1 - Médias e regressões das perdas relativas dos parâmetros de crescimento da matéria fresca (MFPA) e seca (MSPA) da parte aérea do meloeiro em função da condutividade elétrica da solução nutritiva $\left(\mathrm{CE}_{\mathrm{s}}\right)$ para as diferentes fases de exposição à salinidade.

\begin{tabular}{|c|c|c|c|}
\hline \multirow{2}{*}{$\begin{array}{l}\text { Fases de exposição à } \\
\text { salinidade (DAT) }\end{array}$} & \multirow{2}{*}{ 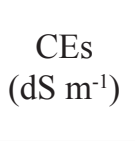 } & \multicolumn{2}{|c|}{ Parâmetros de crescimento } \\
\hline & & $\begin{array}{c}\text { MFPA } \\
\left(\text { g planta }^{-1}\right)\end{array}$ & $\begin{array}{c}\text { MSPA } \\
\left(\text { g planta }^{-1}\right)\end{array}$ \\
\hline \multirow{4}{*}{$\begin{array}{c}10-30 \\
\text { Desenvolvimento } \\
\text { Vegetativo }\end{array}$} & 1,1 & 669,3 & 159,3 \\
\hline & 2,5 & 640,7 & 120,0 \\
\hline & 4,0 & 575.7 & 108,0 \\
\hline & 5,5 & 544,6 & 108,0 \\
\hline \multicolumn{4}{|c|}{$\operatorname{MFPA}(\%)=-4,3 \mathrm{CE}_{\mathrm{s}}+104\left(\mathrm{R}^{2}=0,97\right)$ e $\operatorname{MSPA}(\%)=-6,9 \mathrm{CE}_{\mathrm{s}}+100\left(\mathrm{R}^{2}=0,77\right)$} \\
\hline \multirow{3}{*}{$\begin{array}{c}31-50 \\
\text { Florescimento }\end{array}$} & 2,5 & 638,7 & 113,0 \\
\hline & 4,0 & 585,0 & 103,0 \\
\hline & 5,5 & 549,0 & 98,0 \\
\hline \multicolumn{4}{|c|}{$\operatorname{MFPA}(\%)=-4,1 \mathrm{CEs}+104\left(\mathrm{R}^{2}=0,9\right)$ e MSPA $(\%)=-8,1 \mathrm{CEs}+100\left(\mathrm{R}^{2}=0,79\right)$} \\
\hline \multirow{3}{*}{$\begin{array}{c}\text { 51-70 } \\
\text { Frutificação }\end{array}$} & 2,5 & 658,0 & 145,3 \\
\hline & 4,0 & 640,0 & 129,7 \\
\hline & 5,5 & 567,7 & 121,0 \\
\hline \multicolumn{4}{|c|}{$\operatorname{MFPA}(\%)=-3,2 \mathrm{CEs}+105\left(\mathrm{R}^{2}=0,8\right)$ e MSPA $(\%)=-5,5 \mathrm{CEs}+105\left(\mathrm{R}^{2}=0,98\right)$} \\
\hline
\end{tabular}


TABELA 2 - Média e regressão dos parâmetros de produção, massa média de frutos (MMF) e espessura de polpa (EP) do meloeiro em função da condutividade elétrica da solução nutritiva $\left(\mathrm{CE}_{\mathrm{s}}\right)$ para as diferentes fases de exposição à salinidade.

\begin{tabular}{|c|c|c|c|}
\hline \multirow{2}{*}{$\begin{array}{l}\text { Fases de exposição à } \\
\text { salinidade (DAT) }\end{array}$} & \multirow{2}{*}{ 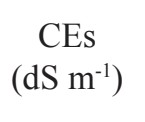 } & \multicolumn{2}{|c|}{ Parâmetros de produção } \\
\hline & & MMF (g fruto $\left.{ }^{-1}\right)$ & $\mathrm{EP}(\mathrm{mm})$ \\
\hline \multirow{4}{*}{$\begin{array}{c}10-30 \\
\text { Desenvolvimento } \\
\text { Vegetativo }\end{array}$} & 1,1 & 963,7 & 38,0 \\
\hline & 2,5 & 949,3 & 35,3 \\
\hline & 4,0 & 772,3 & 34,7 \\
\hline & 5,5 & 680,7 & 33,3 \\
\hline \multicolumn{4}{|c|}{$\mathrm{MMF}=-70,1 \mathrm{CEs}+1071\left(\mathrm{R}^{2}=0,93\right)$ e $\mathrm{EP}=-0,99 \mathrm{CE}_{\mathrm{s}}+38,6\left(\mathrm{R}^{2}=0,92\right)$} \\
\hline \multirow{3}{*}{$\begin{array}{c}31-50 \\
\text { Florescimento }\end{array}$} & 2,5 & 951,0 & 37,3 \\
\hline & 4,0 & 805,7 & 34,3 \\
\hline & 5,5 & 736,0 & 33,3 \\
\hline \multicolumn{4}{|c|}{$\mathrm{MMF}=-56,6 \mathrm{CE}_{\mathrm{s}}+1049,4\left(\mathrm{R}^{2}=0,93\right)$ e $\mathrm{EP}=-1,17 \mathrm{CE}_{\mathrm{s}}+39,5\left(\mathrm{R}^{2}=0,94\right.$} \\
\hline \multirow{3}{*}{$\begin{array}{c}51-70 \\
\text { Frutificação }\end{array}$} & 2,5 & $900,0 \mathrm{a}$ & 35,3 \\
\hline & 4,0 & 701,0 & 32,3 \\
\hline & 5,5 & 562,7 & 31,0 \\
\hline \multicolumn{4}{|c|}{$\mathrm{MMF}=-95,6 \mathrm{CE}_{\mathrm{s}}+1095\left(\mathrm{R}^{2}=0,97\right)$ e $\mathrm{EP}=-1,63 \mathrm{CEs}+39,49\left(\mathrm{R}^{2}=0,97\right)$} \\
\hline
\end{tabular}

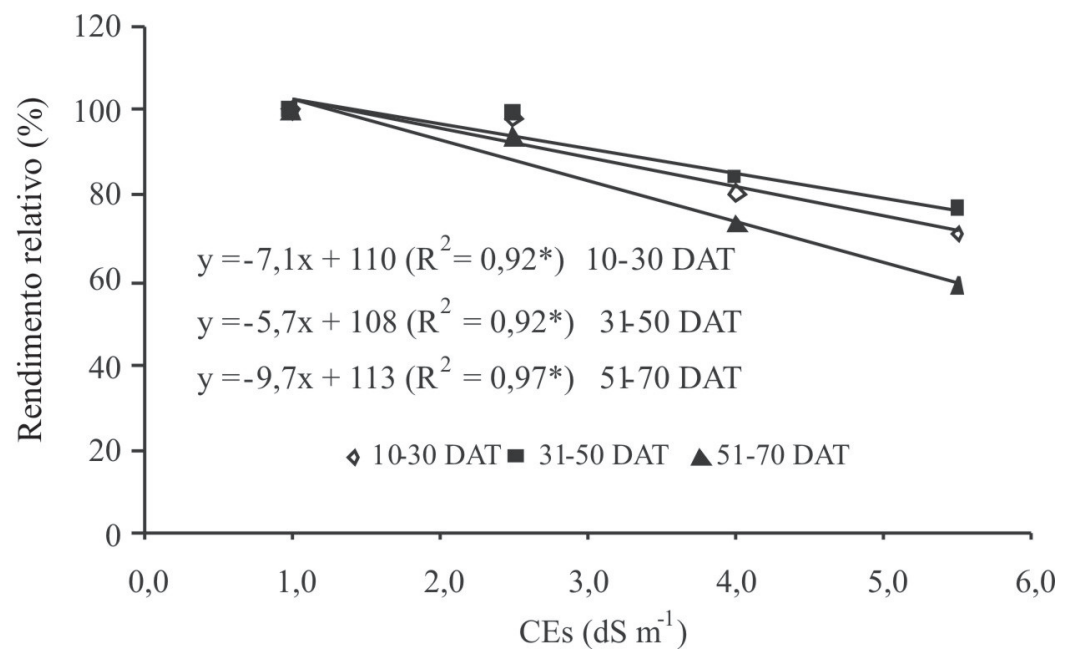

FIGURA 1 - Rendimento relativo do meloeiro para as fases de exposição à salinidade com solução nutritiva de diferentes condutividades elétricas. 


\section{CONCLUSÕES}

Considerando-se o cultivo do meloeiro em substrato de fibra de coco e sob ambiente protegido, as principais conclusões deste trabalho são:

1- Plantas de meloeiro têm o crescimento, a massa de frutos e a espessura da polpa dos frutos linearmente reduzidos, quando submetidas à solução nutritiva com condutividade elétrica acima de $1,1 \mathrm{dS} \mathrm{m}^{-1}$.

2-Plantas de melão submetidas a soluções nutritivas, durante a fase de frutificação, de desenvolvimento vegetativo ou de florescimento, deixam de acumular massa total nos frutos às taxas de 95,6 $\mathrm{g}_{\text {fruto }^{-1}}, 70,1 \mathrm{~g}$ fruto $^{-1}$ ou $56,6 \mathrm{~g}_{\text {fruto }^{-1}}$, respectivamente, para cada acréscimo unitário da $\mathrm{CE}_{\mathrm{s}}$ acima de $1,1 \mathrm{dS} \mathrm{m}^{-1}$.

3- As soluções nutritivas preparadas com água salobra, resultando em condutividade elétrica acima de $1,1 \mathrm{dS} \mathrm{m}^{-1}$, podem ser utilizadas no cultivo do meloeiro em substrato de fibra de coco com as menores perdas de massa média de frutos por incremento de $\mathrm{CE}_{\mathrm{s}}$, quando aplicadas na fase de florescimento.

\section{AGRADECIMENTOS}

Os autores agradecem ao Conselho Nacional de Pesquisa e Tecnologia (CNPq). Projeto de pesquisa financiado com recursos do $\mathrm{CNPq} /$ Edital Universal (Processo n. 486242/2006-4).

\section{REFERÊNCIAS}

ALENCAR, R. D.; PORTO FILHO, F. Q.; MEDEIROS, J. F.; HOLANDA, J. S.; PORTO, V. C. N.; FERREIRA NETO, M. Crescimento de cultivares de melão amarelo irrigadas com água salina. Revista Brasileira de Engenharia Agrícola e Ambiental, Campina Grande, v. 7, n. 2, p. 221-226, 2003.

AMOR, F. M. del.; MARTINEZ, V.; CERDÁ, A. Salinity duration and concentration affect fruit yield and quality, and growth and mineral composition of melon plants in perlite. HortScience, Alexandria, v. 34, n. 7, p. 1234-1237, 1999.

AYERS, R. S.; WESTCOT, D. W. A qualidade da água na agricultura. Tradução de H.R Gheyi; J.F. Medeiros; F.A.V. Damasceno. Campina Grande: UFCG, 1999. 218p. (Estudos FAO Irrigação e Drenagem, 29).
CRUZ, C.D.; REGAZZI, A.J. Modelos biométricos aplicados ao melhoramento genético. 2.ed. Viçosa: UFV, 2001. 390p.

DIAS, N. S.; DUARTE, S. N., MEDEIROS, J. F.; TELES FILHO, J. F. Salinidade e manejo da fertirrigação em ambiente protegido. II: Efeitos sobre o rendimento do meloeiro. Revista Irriga, Botucatu, v. 11, n. 3, p. 376-383, 2006.

DIAS, N. DA S.; DUARTE, S. N.; TELES FILHO, J. F.; YOSHINAGA, R. T. Salinização do solo por aplicação de fertilizantes em ambiente protegido. Revista Irriga, Botucatu, v. 12, n. 1, p. 135-143, 2007.

FAGERIA, N. K.; GHEYI, H. R.; SOARES FILHO, W. S. Manejo da Salinidade na agricultura: estudos básicos e aplicados. In: GHEYI, H. R.; DIAS, N. S.; LACERDA, C. F. Melhoramento genético vegetal e seleção de cultivares tolerantes à salinidade. Fortaleza: INCTsal, 2010. cap. 13, p. 212-225.

FURLANI, P. R.; SILVEIRA, L. C. P.; BOLONHEZI, D.; FAQUIN, V. Cultivo hidropônico de plantas. Campinas: Instituto Agronômico, 1999. 52p. (Boletim Técnico, 180).

LÄUCHLI, A.; EPSTEIN, E. Plant responses to saline and sodic conditions. In: TANJI, K. K. Agricultural salinity assessment and management. New York: American Society of Civil Engineers, 1990. cap. 6, p. 113-137.

MAAS, E. V.; HOFFMAN, G. J. Crop salt tolerance: current assessment. Journal of Irrigation and Drainage, New York, v.103, n.02, p.115-134, 1977.

MAAS, E. V. Crop salt tolerance. In: TANJI, K. K. Agricultural salinity assessment and management. New York: American Society of Civil Engineers, 1990. cap. 13, p. 262-304.

MEDEIROS, J. F.; LISBOA, R. A.; OLIVEIRA, M.; SILVA JÚNIOR, M. J. DA.; ALVES L. P. Caracterização das águas subterrâneas usadas para irrigação na área produtora de melão da Chapada do Apodi. Revista Brasileira de Engenharia Agrícola e Ambiental, Campina Grande, v. 7, n. 3, p. 469472, 2003. 
SANTOS, R. N. C. Avaliação da relação K:N e híbridos de melão em cultivo hidropônico. 2002. 98 f. Dissertação (Mestrado em Fitotecnia) - Escola Superior de Agricultura "Luiz de Queiros", Universidade de São Paulo, Piracicaba, 2002.

SAS INSTITUTE. SAS user's guide. Version 9.0. Cary: SAS Institute, 2000. 584p.
SOARES, T. M.; SILVA, E. F. F.; DUARTE, S. N.; MÉLO, R. F.; JORGE, C. A; BONFIM-SILVA, E. M. Produção de alface utilizando águas salinas em sistema hidropônico. Revista Irriga, Botucatu, v. 12, n. 2, p. 235-248, 2007.

TAIZ, L.; ZEIGER, E. Fisiologia vegetal. 3.ed. Porto Alegre: Artmed, 2006. 719p. 